\title{
Evaluation Of Epithelization When Amniotic Membrane Use As A Biologic Dressing In Oral Cavity
}

\author{
Anisuzzaman $\mathrm{M} \mathrm{M}^{1}$, Khan $\mathrm{S} \mathrm{R}^{2}$, Ahmed $\mathrm{A} \mathrm{U}^{3}$, Wahiduzzaman $\mathrm{M}^{4}$, Sarker $\mathrm{M} \mathrm{A}^{5}$, Khan M T ${ }^{6}$
}

Received: 12.02 .18

Accepted: 15.04 .18

\section{Abstract:}

Abstract:

Background:Skin act as a protective barrier to prevent the contamination from environment and dehydration of tissue. After any surgery to the oral cavity, wound closure or reconstruction is mandatory which is done by skin graft and skin substitute like amniotic membrane by the process of epithelialization and tissue regeneration. Amniotic membrane is use as skin substitute in burn, eye and oral cavity as biologic wound dressing.

Objective:To evaluate the epithelialization after use of amniotic membrane in mucosal defect of oral cavity as a biologic dressing.

Methods:This was a prospective study which included 26 with premalignant lesion in buccal mucosa who under went excision of the lesion from intraoral buccal mucosa between January 14-june 15 and post operative follow up for 4-6 month after the surgical procedure. We used amniotic membrane(am) for dressing of the defects in buccal mucosa of oral cavity under local anesthesia. Efficacy of this procedure was assessed by granulation tissue formation with surface epithelialization on the graft site.

Results:The epithelialization evaluated in postoperative period. According to sex 40 males $70 \%$ and 30 females age 22-72 years with means age $45.0 \pm 10.5$ years. After excision of lesion from buccal mucosa amniotic membrane was grafted on the defect. Completeadherence of amniotic membrane in most of the cases. Wound covered by epithelialization was entire wound coverage in $85 \%$ and Nearly entire wound coverage in $15 \%$ when use amniotic membrane use as a biologic dressing in oral cavity. No allergic reaction occurs in any patients.

Conclusion: Amniotic membrane can be useas a skin substitute in buccal mucosa of the oral cavity.

Keywords:Amniotic membrane, Epithelialization, precancerous lesion, oral cavity.

1. Dr. Mostafa Md. Anisuzzaman; FCPS, BDS, Assistant Registrar,Department of Oral and Maxillofacial surgery, Bangladesh Dental College, Dhanmondi, Dhaka.

2. Dr. Safiquer Rahman Khan; BDS, Lecturer, Department of Oral and Maxillofacial surgery, Bangladesh Dental College, Dhanmondi, Dhaka.

3. Dr. Mohammad Tariqul Islam Khan; DDS, BDS, Assistant Professor, Department of Oral Anatomy and Physiology, Bangladesh Dental College, Dhanmondi, Dhaka.

4. Dr. Anser Uddin Ahmed; BDS, Registrar, Department of Oral and Maxillofacial surgery, International Dental College and Hospital, Chittagong.

5. Dr. Md. Wahiduzzaman; MCPS, BDS, Assistant Professor and Head, Department of Oral and Maxillofacial surgery, Dental Unit, Gonosasthyasomajvittik medical college, Savar.

6. Dr. Md. Al-Amin Sarkar; BDS, Assistant Dental Surgeon, Upazila Health Complex Ulipur, Kurigram.

Correspondence : Dr. Mostafa Md. Anisuzzaman, E-mail: dmukul808@gmail.com 


\section{Introduction:}

In 1978 the World Health Organization (WHO) defined leukoplakia as "a white patch or plaque that cannot be characterized clinically or pathologically as any other disease"1. The current definition is that of "a white plaque of questionable risk having excluded (other) known diseases or disorders that carry no increased risk for cancer"2. It is considered as one of the most common premalignant lesion or Potentially Malignant Disorder. ${ }^{3}$

It is a clinicopathological diagnosis that can only be made after histological examination of the tissue. It represents the most common premalignant disease of the oral mucosa. The prevalence varies geographically but also reflects differences in study design and populations studies ${ }^{4}$. The presence of dysplasia in leukoplakia is believed to be associated with a higher probability to transform into oral cancer which increases with the grade ${ }^{5-6}$

The gold standard for the diagnosis and management remains histopathologic assessment from a suspicious lesion. This depends on the quality of the biopsy, patient clinical information, interpretation of biopsy by a pathologist and the correct action by the clinician. The pathologist can only confirm that no other pathology is present and comment on the presence and degree of dysplasia or infiltration ${ }^{4}$.

It is usually treated by surgical excision with a healthy margin. In case of a large mucosal defect after excision of any benign or malignant soft tissue lesion, reconstruction is mandatory. A number of surgical procedures have been advocated for the reconstruction of oral cavity defects after surgery, including primary closure, buccal mucosal graft, split thickness skin graft, buccal pad of fat, allogeneic graft, regional rotational flap and distant flap ${ }^{7}$.

An epithelial defect not responding favorably to routine modalities ofdressings instigated the search of an ideal dressing material, which isbiologic and satisfies certain desirable properties. The ideal dressingshould provide relief from pain, protect wound from secondaryinfection, maintain a moist environment, prevent loss of fluids,promote healing, be elastic and non-antigenic, adhere well to wound,be easy to apply, easily available and economical. ${ }^{8}$

The search for such a material led researchers to human amniotic membrane, which augurs well with expectations. Human amnioticmembrane is a biolog- ic dressing that is non immunogenic because ofits unique characteristic of not expressing major histocompatibilityantigens. Hence it does not evoke an immune response from the host. In addition to that, the membrane produces various growth factorsincluding basic fibroblast growth factor, transforming growthfactors, angiogenic growth factors, all contributing to better re-epithelialization ${ }^{9-10}$.

Human amniotic (AM) has been used as a biomaterial for surgical reconstruction for nearly 100 years. In 1910, Daviswas the first scientist to use amniotic membrane in the skin transplantation ${ }^{11}$.Subsequently, it has been widely used as a surgical dressing in management of burn ${ }^{12-13}$ surgical reconstruction of the bladder ${ }^{14}$ and vagina ${ }^{15}$ and in prevention of surgical adhesions ${ }^{16}$. Amniotic membrane transplantation is also used in a wide variety of ocular disease as a temporary graft in order to promote ocular surface healing by suppressing inflammation, fibrosis and neovascularization ${ }^{17-18}$

The aim of this study was to evaluation of epithelialization after use of amniotic membrane as a biologic wound dressing material surgical defects of buccal mucosa of oral cavity.

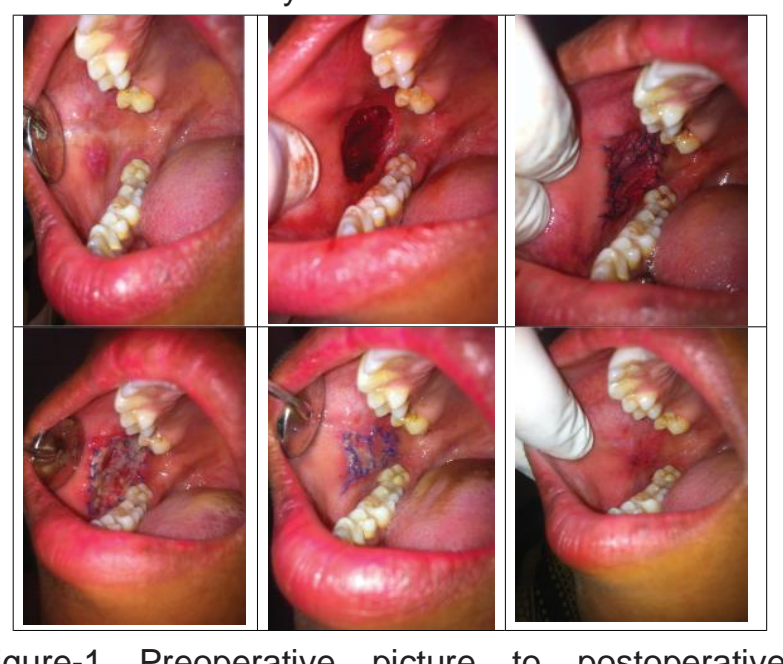

Figure-1 Preoperative picture to postoperative epithelialization. 


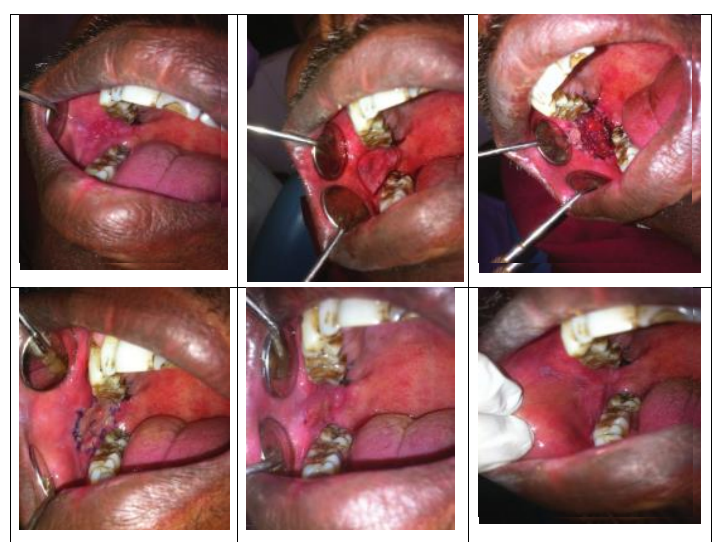

Figure-2 Preoperative picture to postoperative epithelialization.

\section{Method:}

This was a prospective study that included 20 with premalignant lesion in buccal mucosa who underwent excision of the lesion from intraoral buccal mucosa between January 14 and June 15 in Department of Oral and Maxillofacial surgery, BSMMU. The study approved by the Ethical Committee of Bangabandhu Sheikh Mujib Medical University. Location of the lesion was buccal mucosa and Patients with clinically and histo pathologically diagnosed premalignant lesion undergoing surgical management. The amniotic membrane was fixed by Suturing (vicryle $4 / 0$ round) to the underlying mucosal membrane. The patients were followed up for 4-6 months.

Processing and Preservation of Fresh Frozen (800C) Amniotic Membrane Allograft:

Human placenta was collected from healthy and seronegative donor during elective caesarean or vaginal deliveries. Under a laminar flow cabinet amnion membrane was separated from chorion and cleaned blood clots \& other debris from amnion membrane. Then the membrane washed $3 / 4$ times (30 minutes per cycle) using Balanced Salt Solution (BSS) containing antibiotics mixture (penicillin 50 $\mu \mathrm{g} / \mathrm{ml}$, Streptomycin $50 \mu \mathrm{g} / \mathrm{ml}$, gentamycin $25 \mu \mathrm{g} / \mathrm{ml}$ and amphotericin B $2.5 \mu \mathrm{g} / \mathrm{ml}$ ). After washing the amnion membrane was then flattened onto a nitrocellulose paper with a size of $0.22 / 0.45 \mu$ with the epithelium/basement membrane surface up. The membrane with nitrocellulose paper was then cut into $5 \times 5 \mathrm{~cm} 2$ pieces and kept into a sterile vial containing the DMEM (Dublecco's Eagle Modified Medium) and glycerol at the ratio of $1: 1(\mathrm{~V} / \mathrm{V})$. Then the vials containing amnion membrane was stored in -800C deep freezer19. Before clinical applications in tissue banking and biomaterial research unit of Bangladesh atomic energy commission and they supply us before operation. We used amniotic membrane(am) for dressing of the defects in buccal mucosa of oral cavity under local anesthesia and post-operative follow up for 4-6 month after the surgical procedure.. Efficacy of this procedure was assessed by granulation tissue formation with surface epithelialization on the graft site.

\section{Data analysis:}

The data was analyzed with the help of software programmed SPSS version 20 for windows. The comparison between means was done by Independent sample 't' test for continuous variable. The result was considered significant if $p$ value was $\leq 0.05$.

\section{Results:}

The study was conducted in the department of Oral and Maxillofacial Surgery, BSMMU, Dhaka. The study was intended to evaluate the epithelialization after excision of oral pre malignant lesion. The table, bar diagram and pie chart was formed as necessary. Figure 1: Age distribution of the patients $(n=20)$

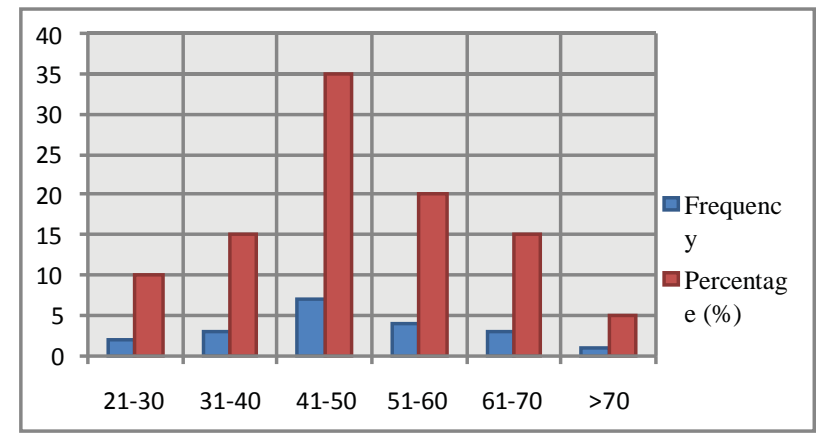

The column diagram showing age frequency actual and percentage. most common age group is $41-50$ years 35\%. Maximum age 72 years and Minimum age 22 Years. Mean $\pm S D$ age of patient is $45.0 \pm 10.5$ years.

Figure 2:Sex distribution of the patients $(n=20)$

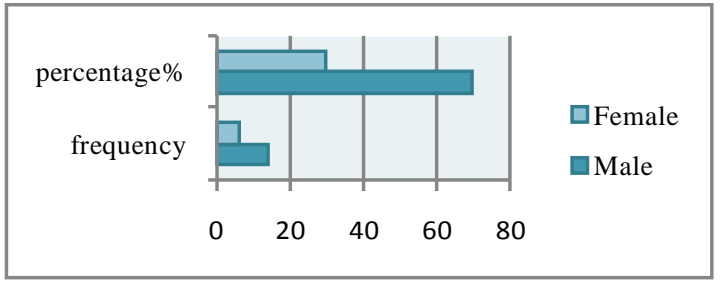


The bar diagram showing the sex distribution of the patients. The diagram shows male $70 \%$ and female $30 \%$.

Table: 1 Assessment of wound coverageafter one month clinically $(n=20)$

\begin{tabular}{|c|c|c|c|}
\hline \multirow[t]{2}{*}{$\begin{array}{l}\text { Wound } \\
\text { coverage }\end{array}$} & \multicolumn{2}{|c|}{$\begin{array}{l}\text { When amniotic membrane used } \\
\text { as a biologic dressing in oral } \\
\text { cavity (n=20) }\end{array}$} & \multirow[t]{2}{*}{$p$ value } \\
\hline & Total & Percentage $\%$ & \\
\hline $\begin{array}{l}\text { Entire wound } \\
\text { coverage }\end{array}$ & 17 & $85 \%$ & \multirow[b]{2}{*}{$0.86^{\mathrm{ns}}$} \\
\hline $\begin{array}{l}\text { Nearly entire } \\
\text { wound } \\
\text { coverage }\end{array}$ & 3 & $15 \%$ & \\
\hline
\end{tabular}

$P$ value measured by Chi-square test, $\mathrm{ns}=$ not significant $\mathrm{n}=$ Number of patient

This table: 1 showswound coverage in whichentire wound coverage in $85 \%$ and Nearly entire wound coverage in $15 \%$ when useamniotic membraneuse as a biologic dressing in oral cavity. The $p$ value is 0.86 , which is not significant.

Table: 2 Assessment of Adherence of amniotic membrane to the defect.

\begin{tabular}{|l|l|l|}
\hline $\begin{array}{l}\text { Adherence of amniotic } \\
\text { membrane }\end{array}$ & Total & Percentage\% \\
\hline Complete adherence & 16 & $80 \%$ \\
\hline Partial adherence & 3 & $15 \%$ \\
\hline Not adherence & 1 & $5 \%$ \\
\hline
\end{tabular}

This table: 2 shows adherence of amniotic membrane to the defect in whichComplete adherence $80 \%$, Partial adherence $15 \%$ and Not adherence $5 \%$ of patients.

No allergic reaction occurs in any patients. The epithelialization was very well in all patients.

\section{Discussion:}

Amniotic membranes have already been used extensively as biologic dressings in ophthalmic, abdominal, and plasticsurgery. The laminin structure of amnion tissue is nearlyidentical to that of native human tissue such as oral mucosa.Reconstruction of a buccal mucosal defect after excision ofspeckled leukoplakia using HAM has been reported with apromising result ${ }^{20}$. Uncoveredwounds are susceptible to infection and prone to scarring and contraction. The moist environment with saliva contamination interfereswith healing process. ${ }^{21,22}$ Autologous regional and distant flap and/or skin graft are routinely used. Allograft donor is not suitable because of rejectionafter a short period of reconstruction. ${ }^{23}$

Collagen membrane was used as graft material to repair defects of mucous membrane in the oral cavity. They recommended that Collagen was an excellent material for graft wound healing. ${ }^{24}$

In our study we used amniotic membrane as a biological dressingfor surgical defect in buccal mucosa of the oral cavity. No special technique followed in our study. Its application was very simple and easy in buccal mucosa defect. In clinical study wound coverage was fine with no recurrence.

In a recent study which was performed by Shojaku, et al. usefulness of human AM patches as a dressing substitute for temporalisfascia graft was investigated in canal wall down tympanoplasty. Complete epithelialization of the mastoid cavity took place in allpatients, as well as complete epithelialization of the AM graft was significantly faster than the facial graft. ${ }^{25}$

Now a days amniotic membrane enhance wound healing and re epithelialization. ${ }^{26}$

Its antimicrobial and anti viral properties ${ }^{27,28}$, low immunogenicity29reduce scarring and inflammation $^{30}$, no rejection of graft $^{31,32}$.

\section{Conclusion:}

So in conclusion we can said that amniotic membrane can be useas a skin substitute in buccal mucosa of the oral cavity.

References:

1. Kramer I R, Lucas R B, Pindborg J J, Sobin L H. Definition of leukoplakiaand related lesions: an aid to studies on oral precancer. Oral Surg OralMed Oral Pathol. 1978; 46(4): 518-39.

2. Warnakulasuriya $\mathrm{S}$, Johnson $\mathrm{N} \mathrm{W}$, van der Waal I. Nomenclature and classification of potentially malignant disorders of the oral mucosa. J Oral Pathol Med. 2007; 36(10): 575-80.

3. Van der Waal I, Schepman K P, Van der Mejj E H, Smeele L E. Oral leukoplakia: a clinicopathological review. Oral Oncl. 1997; 33(5): 291-301.

4. Boy S C. Boy Leukoplakia and erythroplakia of the oral mucosa - a briefoverview. SADJ. 2012; 67(10): p558 p560

5. Warnakulasuriya S, Reibel J, Bouquot J, Dabelsteen E. Oral epithelial dysplasia classification systems: predictive value, utility, weaknesses and scope for improvement. J Oral Pathol Med. 2008; 37(3): 127-33. 
6. Silverman S Jr, Gorsky M, Kaugars G E. Leukoplakia, dysplasia, and malignant transformation. Oral Surg Oral Med Oral Pathol Oral Radiol Endod. 1996; 82(2): 117.

7. Watkinson J C, Gaze M N, Wilson J A. Tumors of lip and oarl cavity, in:Stell and Maran's Head and neck Surgery, 4th edn, Hodder Arnold, London. 2000; Chap.15: pp.302-4

8. Ravishankar R, Bath A S, Roy R, "Amnion Bank"- the use of long term glycerol preserved amniotic membranes in the management of superficial and superficial partial thickness burns. Burns, 2003: 29, 369-374

9. Faulk W P, Matthews R, Stevens P J, Bennet P J, Burgos $\mathrm{H}$, His L B: Human amniotic membrane as an adjunct in wound healing. ve Lancet, May. 1980; Page 1156

10. Akle A C, Adinolfi M, Welsh K I, Leibowitz S, Mccoll I: Immunogenicity of humanamniotic epithelial cells after transplantation into volunteers. \e Lancet, November.1981; Page 1003

11. Davis JW. Skin transplantation with a review of 550 cases at the JohnsHopkins Hospital. Johns Hopkins Med J. 1910; 15: 307.

12. Adly OA, Moghazy AM, Abbas AH, Ellabban AM, Ali OS, MohamedBA. Assessment of amniotic and polyurethane membrane dressings inthe treatment of burns. Burns. 2010; 36: 703-710.

13. Andonovska D, Dzokic G, Spasevska L, Trajkovska T, Popovska K, Todorov I, etal.The advantages of the application of amnion membrane in the treatment of burns. Prilozi. 2008; 29: 183-198.

14. lijima K, Igawa $Y$, Imamura T, Moriizumi T, Nikaido T, Konishi I, et al. Transplantation of preserved human amniotic membrane for bladder augmentation in rats. Tissue Eng. 2007; 13: 513-524.

15. Sarwar I, Sultana R, Nisa RU, Qayyum I. Vaginoplasty by using amniongraft in patients of vaginal agenesis associated with Mayor-Rokitansky-Kuster-Hauser syndrome. J Ayub Med Coll Abbottabad. 2010; 22: 7-10.

16. Arora M, Jaroudi KA, Hamilton CJ, Dayel F. Controlled comparison ofintercede and amniotic membrane graft in the prevention of postoperativeadhesions in the rabbit uterine horn model. Eur J ObstetGynecolReprod Biol. 1994; 55: 179-182.

17. Dua HS, Gomes JA, King AJ, Maharajan VS. The amniotic membranein ophthalmology. SurvOphthalmol. 2004; 49: 51-77.

18. Fernandes M, Sridhar MS, Sangwan VS, Rao GN. Amniotic membrane transplantation for ocular surface reconstruction. Cornea 2005; 24: 643-653.

19. Tseng S C G, Prabhasawat P, Lee S-H. Amniotic membranetransplantation for Conjunctival surface reconstruction. Am J Ophthalmol.1997; 124: 765-74.

20. Sham E, Sultana NS. Biological wound dressing - role ofamniotic membrane. Int J Dent Clin. 2011;3:71-2.

21. Lauer G, Schimming R. Tissue-engineered mucosa graft for reconstructionof the intraoral lining after freeing of the tongue: a clinical and immunohistologicstudy. J Oral Maxillofac Surg. 2001; 59: 169-175.

22. Auluck A, Rosin MP, Zhang L, Sumanth KN. Oral submucous fibrosis, a clinically benign but potentially malignant disease: report of 3 casesand review of the literature. J Can Dent Assoc. 2008; 74:735-740.

23. Girod DA, Sykes K, Jorgensen J, Tawfik O, Tsue T. Acellular dermiscomparedto skin grafts in oral cavity reconstruction. Laryngoscope. 2009; 119:2141-2149.

24. Rastogi S, Modi M, Sathian B. The collagen of collagen membrane as a biodegradable wound dressing material for surgical defects of oral mucosa: a prospective study. J Oral Maxillofac Surg. 2009; 67: 1600-1606.

25. Shojaku $H$, Takakura $H$, Okabe $M$, Fujisaka $M$, Watanabe Y, Nikaido T. Effect of hyperdry amniotic membrane patches attached over the bony surface of mastoid cavities in canal wall down tympanoplasty. Laryngoscope. 2011; 121 : 1953-1957.

26. Shimazaki J, Aiba M, Goto E, Kato N, Shimmura S, Tsubota K. Transplantationof human limbal epithelium cultivated on amniotic membrane for the treatment of severe ocular surface disorders. Ophthalmology. 2002; 109: 1285-1290.

27. Fernandes M, Sridhar MS, Sangwan VS, Rao GN. Amniotic membranetransplantation for ocular surface reconstruction. Cornea. 2005; 24: 643-653.

28. Kjaergaard N, Hein M, Hyttel L, Helmig RB, Schønheyder $\mathrm{HC}$, UldbjergN, et al. Antibacterial properties of human amnion and chorion in vitro. Eur $\mathrm{J}$ ObstetGynecolReprod Biol. 2001; 94: $224-229$

29. Lefebvre S, Adrian F, Moreau P, Gourand L, Dausset J, Berrih-Aknin S,et al. Modulation of HLA-G expression in human thymic and amniotic epithelial cells. Hum Immunol. 2000; 61: 1095-1101.

30. Tseng SC, Li DQ, Ma X. Suppression of transforming growth factor-betaisoforms, TGF-beta receptor type II, and myofibroblast differentiation in cultured humancomeal and limbal fibroblasts by amniotic membrane matrix. J Cell Physiol. 1999; 179: 325-335.

31. Kang JW, Koo HC, Hwang SY, Kang SK, Ra JC, Lee $\mathrm{MH}$, et al. Immunomodulatory effects of human amniotic membrane-derived mesenchymalstem cells. J Vet Sci. 2012; 13: 23-31.

32. Hori J, Wang M, Kamiya K, Takahashi H, Sakuragawa $\mathrm{N}$. Immunologicalcharacteristics of amniotic epithelium. Cornea. 2006; 25: S53-S58. 